\title{
Guest Editorial: Machine learning in and for music
}

\section{Gerhard Widmer}

Springer Science + Business Media, LLC 2006

Erratum to: Mach Learn

DOI: $10.1007 / \mathrm{s} 10994-006-9964-1$

One of the articles in this special issue- "Using duration models to reduce fragmentation in audio segmentation" by Samer Abdallah et al.- - finalized after the editorial to the special issue had already been typeset and published on-line. The paper is thus not mentioned in the editorial. We apologize for this small inconsistency and hope that the readers will take interest in a paper that reports on a promising solution to a hard music analysis problem of great practical importance.

The online version of the original article can be found at http//dx.doi.org/10.1007/s10994-006-9964-1

G. Widmer $(\square)$

Department of Computational Perception, Johannes Kepler Univeristy Linz, Austria and Austrian Research Institute for Artificial Intelligence, Vienna, Austria e-mail: www.cp.jku.at/people/widmer 